\title{
An Interactive Mobile Application to Request the Help of the Nearest First Aider by the Injured
} 今 Areej Alshutayri ${ }^{\mathrm{a}}$, Nahla Aljojo $^{\mathrm{b}}$, Basma Alharbi $^{\mathrm{a}}$, Ameen Banjar $^{\mathrm{b}}$, Atheer Alshehri ${ }^{\mathrm{a}}$, Mashaiel Alargoubi ${ }^{\mathrm{a}}$, Ola Barradh ${ }^{\mathrm{a}}$, and Rahaf Helabi ${ }^{\mathrm{a}}$

${ }^{a}$ College of Computer Science and Engineering, Department of Computer Science and Artificial Intelligence, University of Jeddah, Jeddah, Saudi Arabia

${ }^{b}$ 2Department of Information Systems and Technology, College of Computer Science and Engineering, University of Jeddah, Jeddah, Saudi Arabia : aoalshutayri@uj.edu.sa,nmaljojo@uj.edu.sa, bmalharbi@uj.edu.sa, abanjar@uj.edu.sa

KEYWORD

\section{ABSTRACT}

Saudi Arabia is interested in providing health care and ambulatory for all citizens, First aid assistance; residents and tourists of the pilgrims and pilgrims, and it is cooperating with the Saudi Mobile Application; Emergency;

ASAFNY;

Red Crescent Authority (SRCA) to provide emergency health care especially for the pilgrims, Ammar - an independent body dealing with this. The efforts of SRCA can be highly noticed during on the Hajj season and public events such as the national day celebrations (Authority, 2018b). The main issue lies in the fact that despite their efforts, the Ambulance Response Time (ART) remains higher than the global standard. Moreover, the reasons behind the high ART are circumstantial and thus hard to maneuver or manipulate. Therefore, to benefit from the Red Crescent's efforts and the first aid courses they offer, a system where credible first aiders can be summoned to provide proper and faster first aid to the injured is suggested. The aims of this study to develop an application to request the help of the nearest first aider by the injured or bystanders close to the injured. Also, to develop an interface that shows the route to get to the victim.

\section{Introduction}

There are studies on delays in the clinical handover of patient care from emergency medical services (EMS) to hospitals because of the delayed arrival of the ambulance. Some of these studies were conducted to quantify handover delays experienced by the ambulance service, and to investigate patient and system factors associated with handover delay (Authority, 2018a), and are most pronounced at large hospitals, such as King Fahd Hospital in Jeddah.

One study was found that underuse of ambulance and difficult access to patients is one of the factors associated

Advances in Distributed Computing and Artificial Intelligence Journal

(c) Ediciones Universidad de Salamanca / cc by-nc-nd

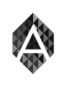

ADCAIJ, Regular Issue Vol 3 n.3 (2015) http://adcaij.usal.es 
with late arrival of them to emergency departments in Saudi Arabia (for Statistics, 2017). Another is worth noting that both the Saudi population and hajj pilgrims are increasing annually. Urgent community-based interventions are needed to address those factors.

Study of predicting ambulance time of arrival in the emergency department using global positioning system and Google maps, was used to derive and validate a model that accurately predicted ambulance arrival time that could be implemented as a Google Maps web application. Accurately predicting ambulance time of arrival in the emergency department (ED) is important for effective resource management, especially for critical patients. Currently, there are no ads available for the EMS crew or ED staff to reliably estimate the ambulance time of arrival (Aljaber, 2018).

According to the annual report of 2015, the Ambulance Response Time (ART) fell between 13-16 minutes inside the cities and 15-18 minutes outside the cities. The authority tried to lower the ART to meet the standard ART which is a maximum of 6 minutes; that is when the brain functions start to shut down in cases of low oxygen supply (Authority, 2018a). In 2017 however, according to Al-Riyadh newspaper, a study of the Red Crescent Authority reports that $70 \%$ of car accident deaths could have been avoided if the paramedics were able to intervene within 30 minutes (Alblwi, 2017).

According to (Alblwi, 2017), the main causes of the prolonged ART time are:

(1) Traffic (Curious bystanders and traffic congestion).

(2) Geographic Location (hard to reach places, unclear addresses).

(3) Shortage (83 ambulance vehicles, 540 trained paramedics, 384 ambulance centers).

Moreover, according to the 2030 vision of Saudi Arabia, it is expected to accommodate up to 30 million pilgrims. The increase in both the population and the pilgrims will cause a strain on the SRCA efforts which will require more efficient solutions to hold on to its goal and noble message.

Essentially, the problem at hand is to find a way to provide the means of getting the proper first aid administration to the injured while waiting for the ambulance. An approach where the causes turn into a solution would be the most helpful, since the nature of the delay causes makes them hard to control or to expect.

Therefore, the main goal of our study is designing application system called My Nearest Aider that connects between two stakeholders which are the aider and the injured/bystander. It also helps people to provide their services to those wishing to benefit from them. Moreover, to ensure an efficient and suitable treatment, the aiders should have legitimate qualifications and should be classified based on them. The project serves two stakeholders which are the first aider and the injured/bystander.

The objectives for the injured/bystander:

- To develop an application to request the help of the nearest first aider by the injured or bystanders

- To construct a database with the user's information

- To provide the location of the injury victim through the application

Advances in Distributed Computing and

Artificial Intelligence Journal

(C)Ediciones Universidad de Salamanca / cc by-nc-nd
ADCAIJ, Regular Issue Vol 3 n.3 (2015)

http://adcaij.usal.es 
The objectives for the first aider:

- Create a database for users with credible first aid knowledge

- Develop an application to receive requests of help of nearby injured people or bystanders close to the injured

- To develop an interface that shows the route to get to the victim

We will predict some benefits from those stakeholders. The injured/bystander will contribute to develop the application to request the help of the nearest first aider by the injured or bystanders. Construct a database with the user's information, and also provide the location of the injury victim through the application. The aider will contribute to create a database for users with credible first aid knowledge, receive requests for help of nearby injured people or bystanders close to the injured and develop an interface that shows the route to get to the victim.

\section{Problem Definition}

According to the annual report of 2015, the Ambulance Response Time (ART) fell between 13-16 minutes inside the cities and 15-18 minutes outside the cities. The authority tried to lower the ART to meet the standard ART which is a maximum of 6 minutes; that is when the brain functions start to shut down in cases of low oxygen supply (Authority, 2018a). In 2017 however, according to Al-Riyadh newspaper, a study by the Red Crescent Authority reports that $70 \%$ of car accident deaths could have been avoided if the paramedics were able to intervene within 30 minutes (Alblwi, 2017).

Essentially, the problem at hand is to find a way to provide the means of getting the proper first aid administration to the injured while waiting for the ambulance. An approach where the causes turn into a solution would be the most helpful, since the nature of the delay causes makes them hard to control or to expect.

\section{Literature Review}

This section presents four different systems that center on two main functions: sharing locations and/or providing first aid. Since these are the substantial elements of the proposed project, conducting a literature review of these systems will be useful to compare. It is worthy to note that, the systems that provide first aid are all authorized by the Red Crescent authority. Each of the following sections will state a short description of the system followed by a list of its main and most profound features.

\subsection{Uber}

Uber is a payed ride sharing application that has two stakeholders: passengers and drivers. Using the application, the passenger could enter their desired destination and request a ride. The system then sends the passengers

Advances in Distributed Computing and

Artificial Intelligence Journal

(C)Ediciones Universidad de Salamanca / cc by-nc-nd

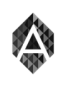

ADCAIJ, Regular Issue Vol 3 n.3 (2015)

http://adcaij.usal.es 
request to nearby drivers until one of them accepts the request and then leads the driver to the passenger's location (Uber, 2019b).

Similarly, the proposed system (My Nearest Aider) aims to connect between the injured and nearby First Aiders. Since Uber is one of the leading ride sharing businesses internationally, it has been chosen as an aesthetic and user experience reference. The most important advantages of Uber are:

- Sharing constant updates of the rides' progress with friends or family, emergency assistance and phone number anonymization (Uber, 2019a).

- The progressive navigation helped expand into a wide range of services, including bicycle sharing, food delivery, shipping trucks and rides on demand (Uber, 2019c).

- Uber also offers the passengers different ways of communications with the driver.

\subsection{ASAFNY}

ASAFNY is an application from Saudi Red Crescent Authority to receive emergency ambulance requests across smartphones on systems (IOS) and (Android). The application supports six different languages, allowing the users to request an ambulance and track it. As well as tracing incident status and facilitate reaching the incident's location for the paramedics (Al-Mrayeh, 2018). The application serves disabled users, such as deaf users to submit a communication without the need to make a call. The application is featured by providing a user registration for the details of their medical history, diseases suffered, and the drugs they use, an urgent distress alert service for the Red Crescent and people close by text messages, inference to nearby medical facilities such as hospitals, dispensaries, and pharmacies in mapping. The most important advantages:

- Share location

- Determine the severity of the situation

- Determine the time of arrival of the ambulance

\subsection{What3Words}

A feature that helps determines the exact location using only three words. The system divided the globe into $3 * 3$ meters and each square was given its own address consisting of three words. For example,"seagull.shorter.hobbit" is the 3 word address of the entrance for the King Abdulaziz Historical Center in Riyadh. This application can help ambulance seekers to determine their location accurately and effectively so that they can say the address by telephone, allowing ambulances to quickly get to the injured location. The Saudi Red Crescent called all pilgrims to download the $\mathrm{W} 3 \mathrm{~W}$ application and get acquainted with it before the previous Hajj season so the pilgrims can share their location in case they need rescue paramedics (What3words, 2019). The most prominent application features:

- Each place has a 3-word special address 
- Instantly compatible with all navigation apps

- Applications provide the voice recognition

- More than 35 languages can use

- Save favorite locations

\subsection{Auto-Answer System}

It is a communion application to the process of automatic response that records and follow up the reports and provided by the caller, it listens to all security news, updates and instructions and record all of them to be broadcast when the citizen and residents call (991) (for Security Operations, 2019). The following are the system objectives:

- Give all citizens and residents the chance to give their opinions and suggestions.

- Encourage citizens and resident to collaborate with security services to provide any information help prevent and detect crime before it occurs.

- Record all calls to ensure follow up.

- Possibility to follow the news and security updates by calling the same number.

- Possibility to know any new security instruction and follow any action on any subject automatically by the phone.

\subsubsection{System Components}

Call Center: This part of the system is known auto answer, it receives the call from citizen with welcome message and show all service options provided by the system and the caller can choose what he want from the system by clicking on the number of basic choices (for Security Operations, 2019):

- Reports and security information

- Remark and suggestions

- Security events

- Emergency numbers

- Sheriff conversation directly

Security reports: It is follow ups and updates security news an integrated application to record security reports' notes and visuals, accord the security events and news. The app features in case of connection for the purpose of reporting, the security notification screen opens (for Security Operations, 2019): 
- Security reports updates

- Notes and visuals

- News and security events

- Configure the application to record all fixed status data

- General reports

Table 1 presents a comparison between the previous four systems and the suggested project (My Nearest Aider). The comparison will include four different criteria that concern the project.

Table 1: Comparison between our project and related work.

\begin{tabular}{l|c|c|c|c|c} 
Criteria & Uber & ASAFNY & What3Words & Auto-Answer System & My Nearest Aider \\
\hline Share Location & Yes & Yes & Yes & Yes & Yes \\
Direct Conversation & & Yes & & Yes & Yes \\
Information of user & & Yes & & & Yes \\
Accept Request & Yes & & & & Yes
\end{tabular}

\section{Methodology}

According to (Igwenagu, 2016), the overall methodology for the research consisted of four stages as outlined below.

Stage 1: Review of literature and previous works on the Nearest Aider Application.

Stage 2: Prior Questionnaire: To ensure a system that provides a proper user experience, a survey consisting of 10 questions was established using google forms. Because the targeted demographic is the citizens in Saudi Arabia, the questionnaire was established in Arabic to assure clearer and wider responses. The questionnaire was distributed using WhatsApp, E-mail, and Apple's Air Drop and gained 267 responses.

Stage 3: Design and implementation of the application: The user interface design specifies how the user; first aider and the database administrator will move through the system. The designs make up a low fidelity prototype to fill up gaps and detect errors before the next phase. The current system is an independent idea in the concept phase. For a clearer reflection on how it would be implemented by a health sector or organization, we used the Saudi Red Crescent Authority as an example and exclusively for simulation purposes.

Stage 4: Usability testing: Usability testing is the relation between the tools and the user they allow patrons to perform tasks or uses in the best possible way. This means that it can be used by the beneficiaries. It is the degree of success of the beneficiary in learning and using the product to achieve a specific goal. 


\section{RESPONDENTS WITNESSING TRAFFIC ACCIDENTS}

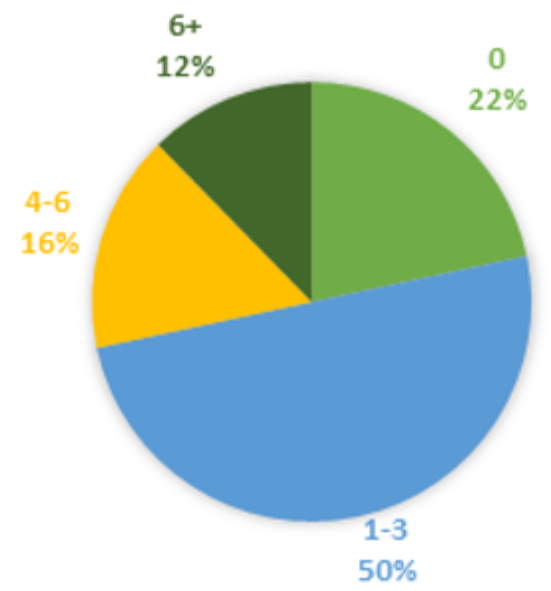

Figure 1: Frequency of witnessed road accidents.

\section{Results of Prior Questionnaire}

Based on the responses from the questionnaire, the largest age demographic is between 20 and 30 years old and they account for $72 \%$ of the total responses For the sex, the number of female respondents surpassed the male respondents with a percentage of $79 \%$ and $21 \%$ respectively.

\subsection{Witnessing Accidents}

To emphasize the frequency of situations where a person becomes a bystander to a serious accident or injury, the questionnaire asks the respondents to approximate how many car accidents they have witnessed on the road as shown in Figure 1. The findings are presented in Figure 2, showcasing that males tend to have witnessed more accidents than females.

\subsection{First Aid and Ambulance}

The questionnaire explores the experience of the respondents with needing first aid or an ambulance as shown in Figure 3.

When asked if they ever needed to call an ambulance, only $33 \%$ of the respondents answered with Yes as shown in Figure 4. 


\section{RELATIONSHIP BETWEEN SEX AND THE FREQUENCY OF WITNESSED ACCIDENTS}

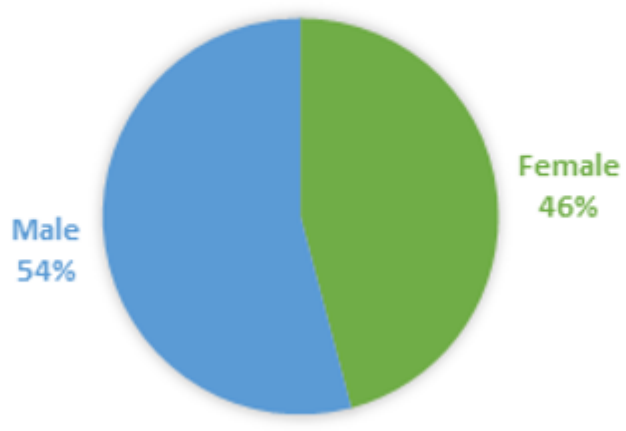

Figure 2: Average of witnessed accidents for each sex.

\section{HAVE YOU EVER BEEN IN A SITUATION WHERE YOU OR SOMEONE CLOSE TO YOU REQUIRES FIRST AID?}

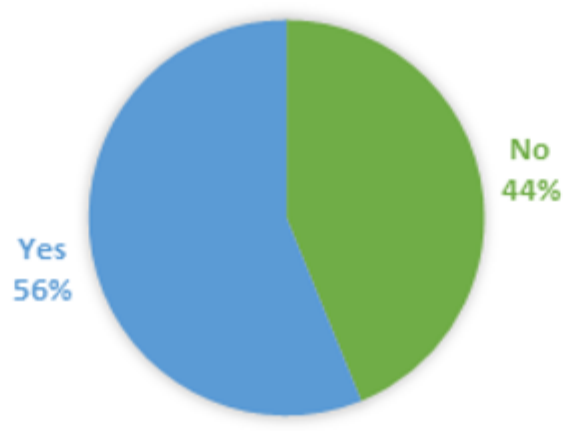

Figure 3: Pie chart depicting respondents' past needs of first aid.

Advances in Distributed Computing and Artificial Intelligence Journal (C)Ediciones Universidad de Salamanca / cc by-nc-nd
ADCAIJ, Regular Issue Vol 3 n.3 (2015) http://adcaij.usal.es 


\section{HAVE YOU EVER NEEDED TO CALL AN AMBULANCE FOR YOU PERSONALLY OR FOR SOMEONE CLOSE TO YOU?}

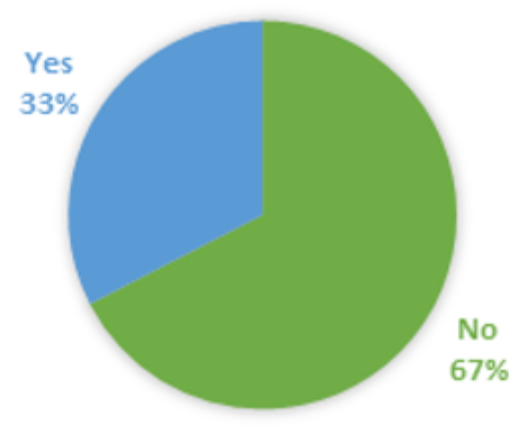

Figure 4: Pie chart depicting respondents' past experience with requesting an ambulance.

The questionnaire ventures more on the experience of the respondents who requested ambulances by asking them how long it took for the ambulance to arrive. Since the ART (Ambulance Response Time) must not be longer than 6 minutes, the format of a short answer question is chosen to allow respondents to submit precise timings. It is worth noting that the question was an optional question because not all respondents needed an ambulance and some did not know the exact timing. In total, 67 respondents were able to provide eligible answers of the time it took the ambulance to arrive.

Those who submitted a time range were replaced with the average of that time range. After organizing the responses and mapping each time frame with the number of responses, it resulted in the following Figure 5.

\subsection{Nearest Aider Application}

When asked to rate how would they feel in a situation where in need of an ambulance, and a first aider is by their side, 217 of the total respondents gave a rating of 5 conveying that they would feel very good. More than half of the respondents gave a rating of 3 or above while the lower rates equaled to a total of 10 respondents. The preceding numbers can be seen in Figure 6.

However, the respondents also seemed to think that first aid is of very high importance with 285 giving it a rating of 5. Figure 7 shows the staggering numbers.

Finally, the respondents were asked about their opinion on implementing an application that links between injury, victims or bystanders with first aiders as shown in figure 8. 


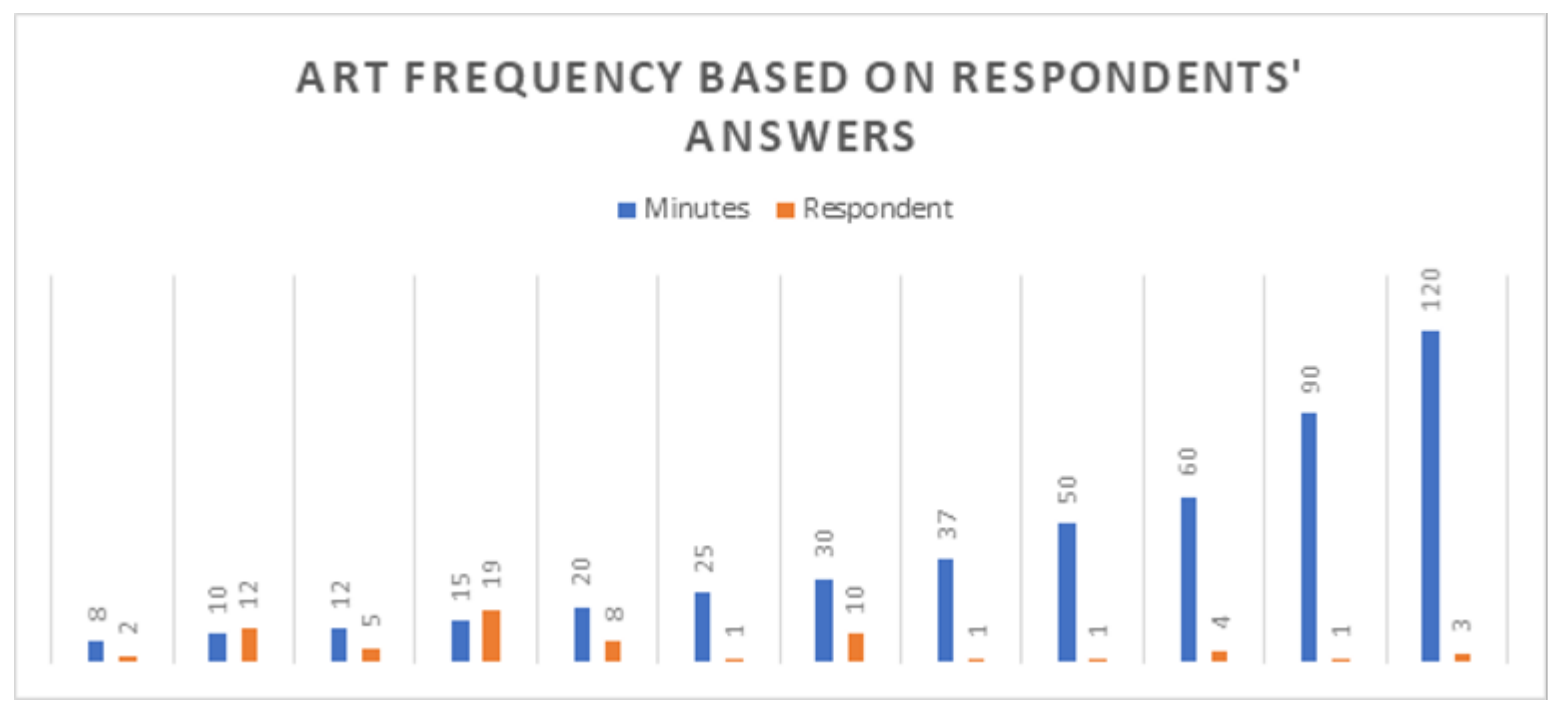

Figure 5: Ambulance response time count based on respondents' experience.

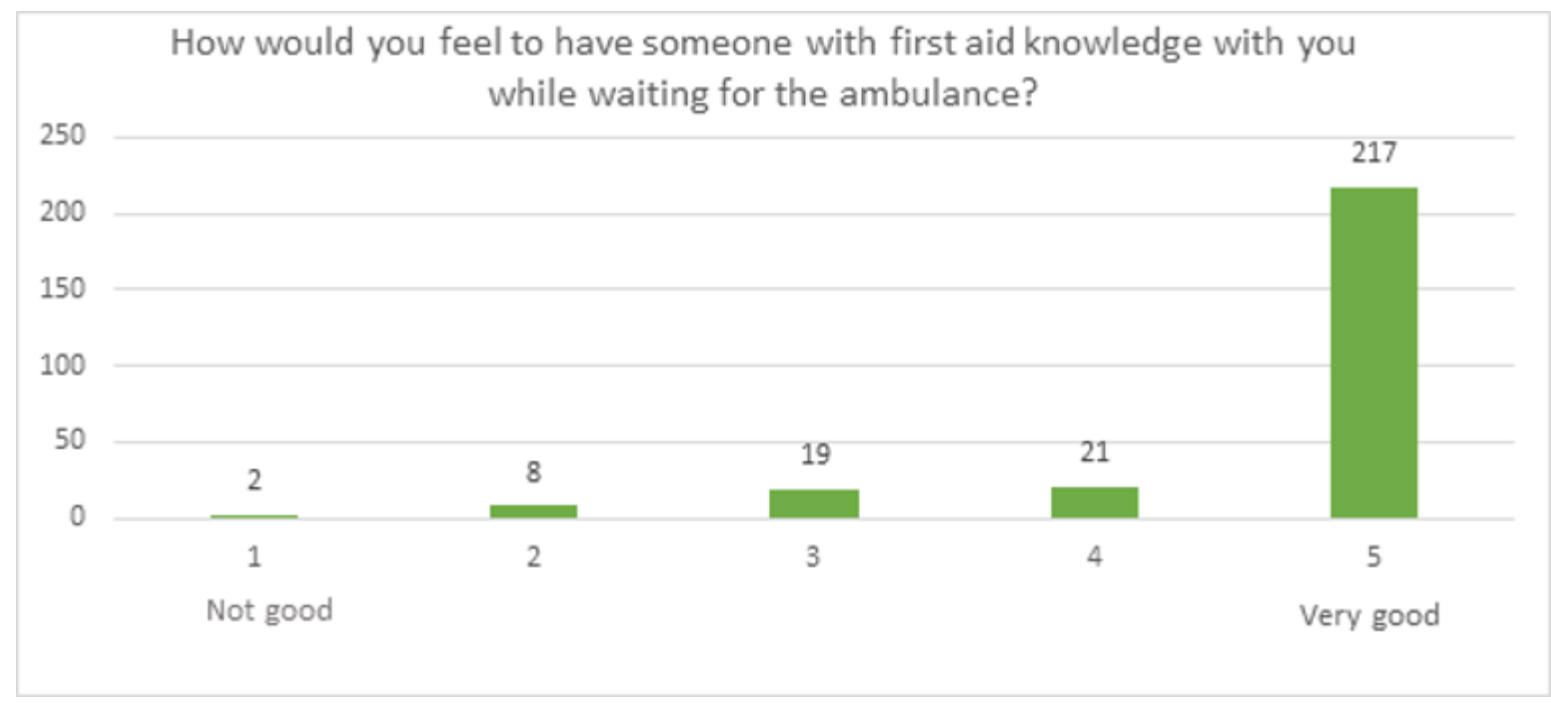

Figure 6: Ambulance response time count based on respondents' experience.

Advances in Distributed Computing and Artificial Intelligence Journal (c)Ediciones Universidad de Salamanca / cc by-nc-nd

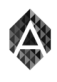

ADCAIJ, Regular Issue Vol 3 n.3 (2015) http://adcaij.usal.es 


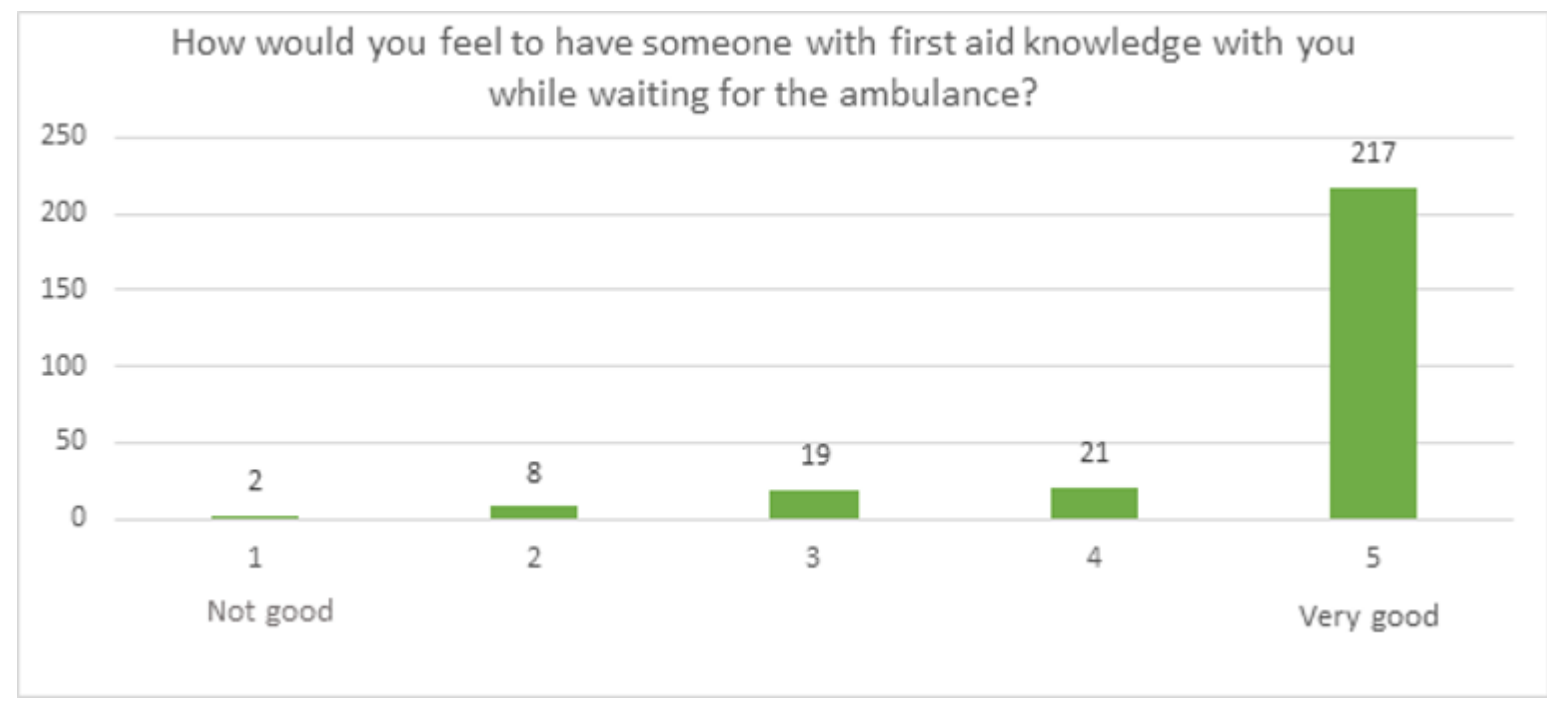

Figure 7: Respondents' opinion on the importance of first aid.

\section{DO YOU WANT TO HAVE AN APPLICATION LINKING THE INJURED AND THE NEAREST VOLUNTEER EXPERIENCED IN FIRST AID?}

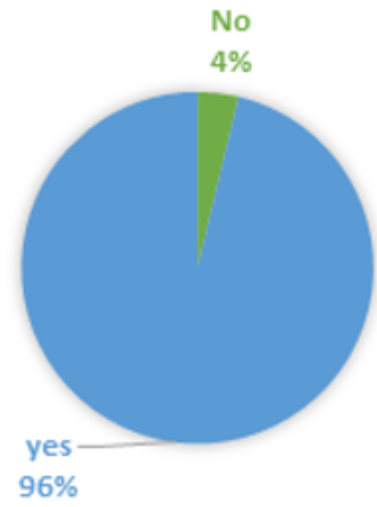

Figure 8: Illustrating the percentages of people in favor and against My Nearest Aider. 


\section{Design and Implementation of the Application}

\subsection{Design of the Application}

In this section, two sequence diagrams are presented to display how different actors connect to the system and to each other. First, the paramedic registers to system. The database admin logs into their system to browse the paramedic information. If the paramedic passes authentication, the system generates and sends an ID to the paramedic for future $\log$ in. The paramedic can update his personal information manually while any information about handled cases are updated automatically. This sequence is represented in Figure 9.

As for Figure 10, the user registers with his phone number to initiate a help request. After receiving the request, the paramedic can see more information about the case before they accept or reject the request. If accepted, the paramedic will be able to see the user's current location. The user will be able to rate the paramedic's performance once they finish treating the injury.

\subsection{Implementation of Application}

This section represents the processes pursued to implement a functional high-fidelity prototype. Section 6.2.1 lists the technologies, programming languages, and tools used in the implementation process. Furthermore, section 6.2.2 will present and describes the main implemented interfaces and their workflow.

\subsubsection{Programming Languages and Tools}

The framework of the project consists of a database that contains the information of the Users, Paramedics, and is accessed by a database administrator through a website. Moreover, the Users and Paramedics register and log in using an android application. The following list presents the different tools and programming languages for each part of the system:

- Database

- Microsoft Database SQL Server

- Website

- Microsoft Visual Studio

- Microsoft ASP.NET Web Pages

- Mobile Application

- Android Studio, JAVA and XML

- BlueStacks, an android application emulator 


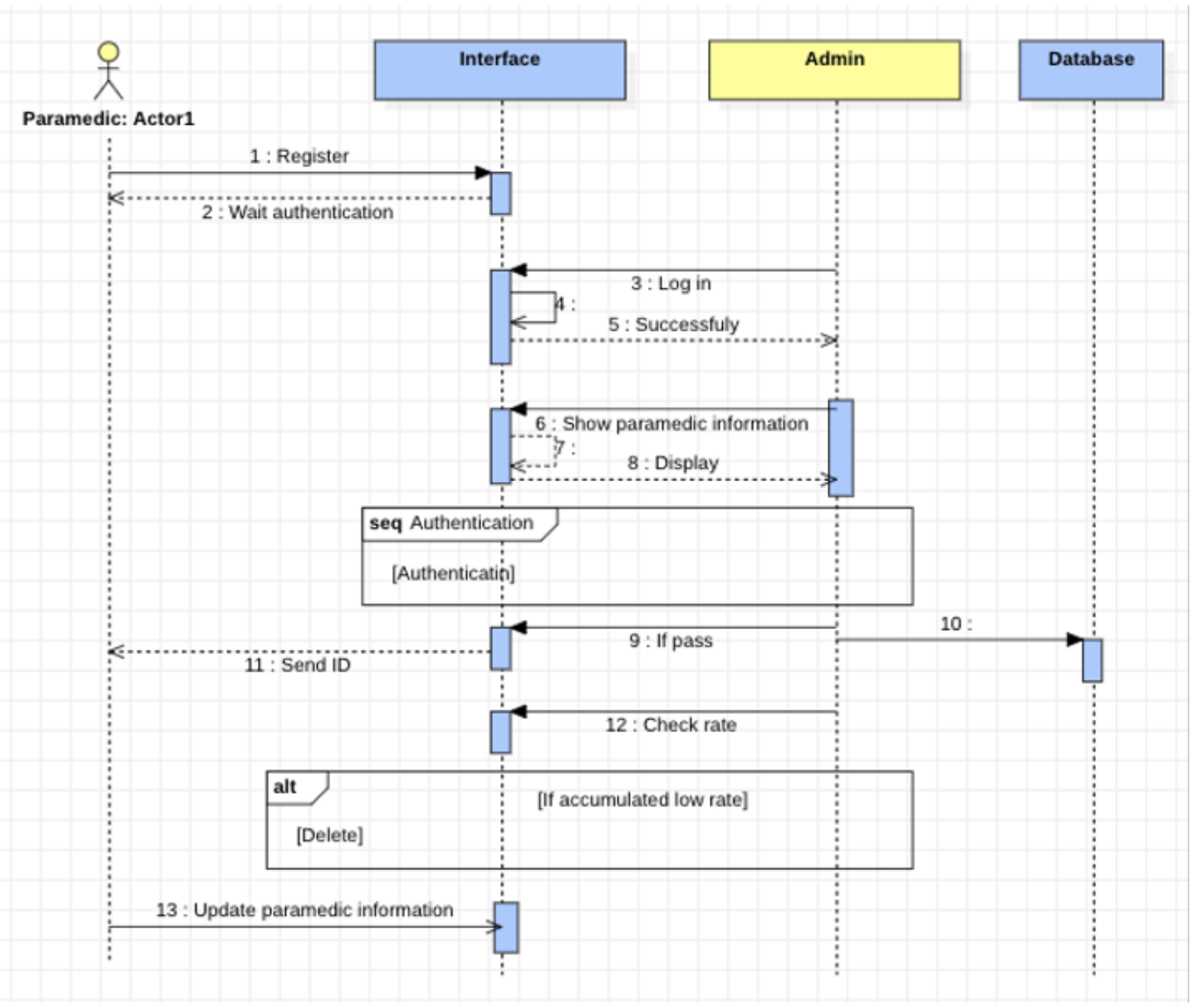

Figure 9: Sequence diagram for Paramedic account.

Advances in Distributed Computing and Artificial Intelligence Journal (c) Ediciones Universidad de Salamanca / cc by-nc-nd
ADCAIJ, Regular Issue Vol 3 n.3 (2015) http://adcaij.usal.es 


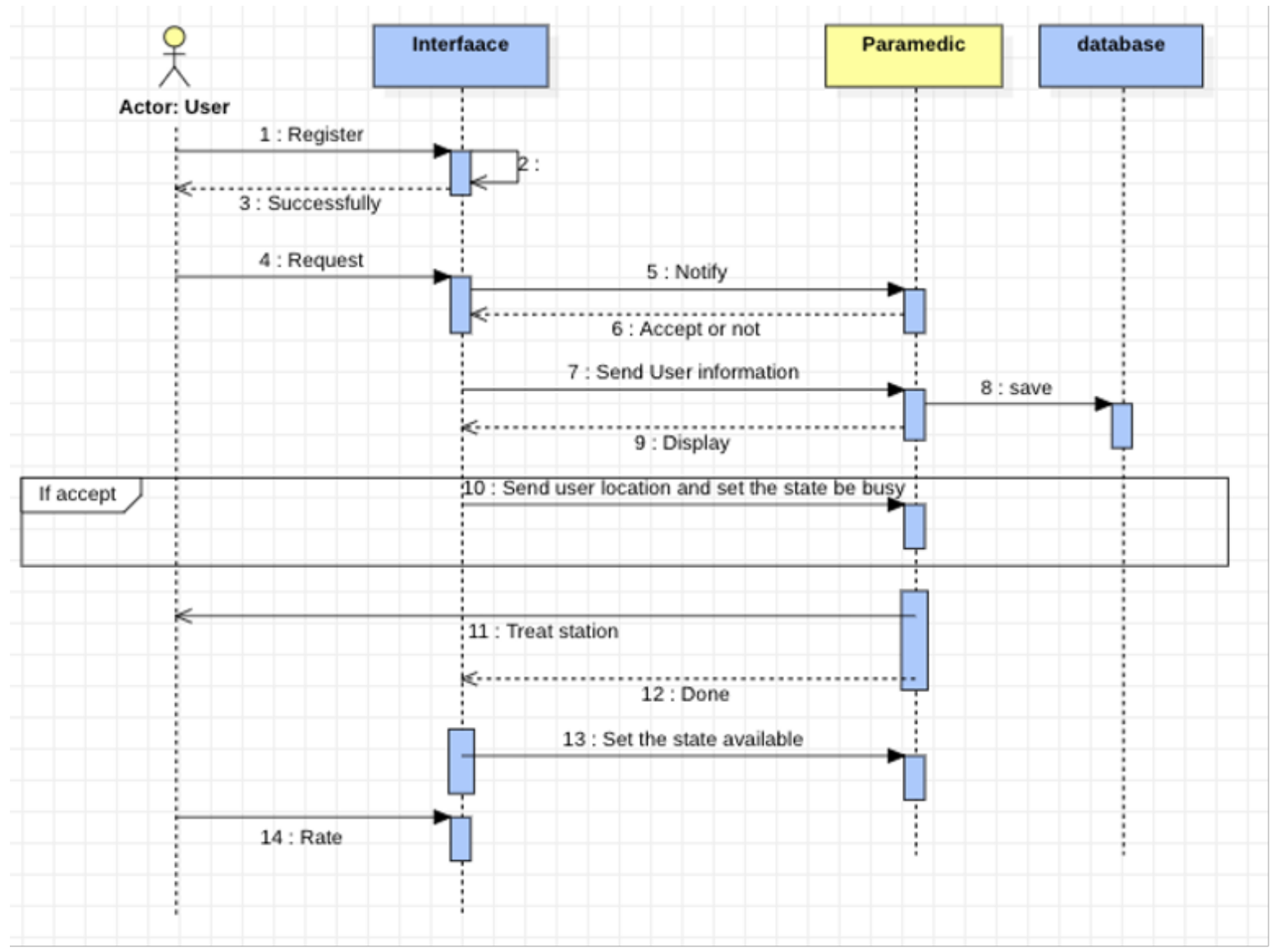

Figure 10: Sequence diagram for Request.

Advances in Distributed Computing and Artificial Intelligence Journal (C)Ediciones Universidad de Salamanca / cc by-nc-nd
ADCAIJ, Regular Issue Vol 3 n.3 (2015) http://adcaij.usal.es 


\subsubsection{System Workflow and Interface Description}

The system mainly consists of a website, an application, and the database. The application is made in two parts; the first part is concerned with the paramedics/aiders while the second one is for the regular users who want to request help. To manipulate the database, Microsoft SQL Server Management Studio allows us to prewrite any required queries in a "Stored Procedures". These procedures receive some parameters from the website and mobile application, which the procedure uses to initiate the written SQL queries. The following figures present the procedures in detail. See figures 11,12 , and 13.

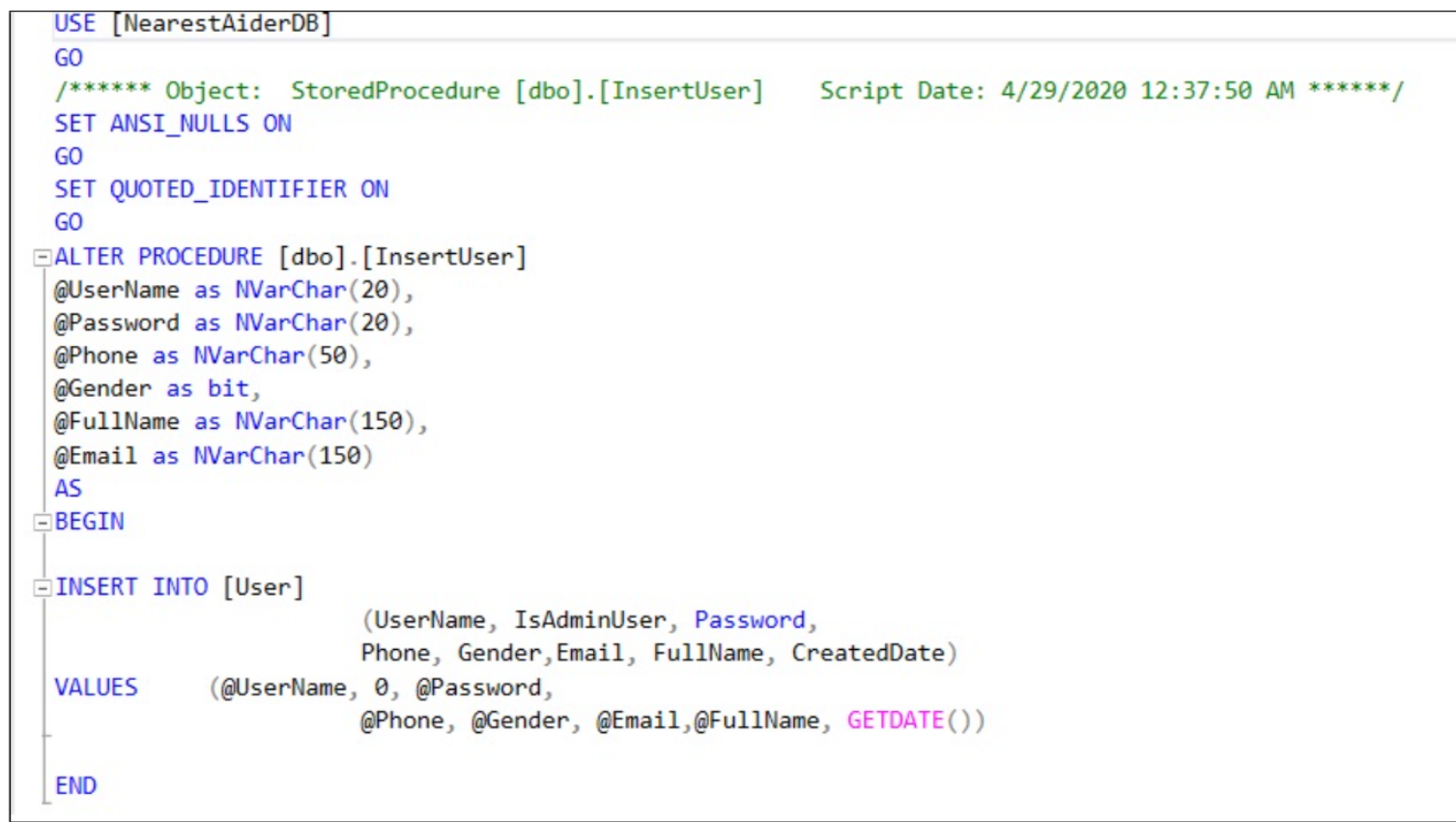

Figure 11: Stored Procedure to INSERT Users into database.

Advances in Distributed Computing and

Artificial Intelligence Journal

(C)Ediciones Universidad de Salamanca / cc by-nc-nd
ADCAIJ, Regular Issue Vol 3 n.3 (2015) http://adcaij.usal.es 


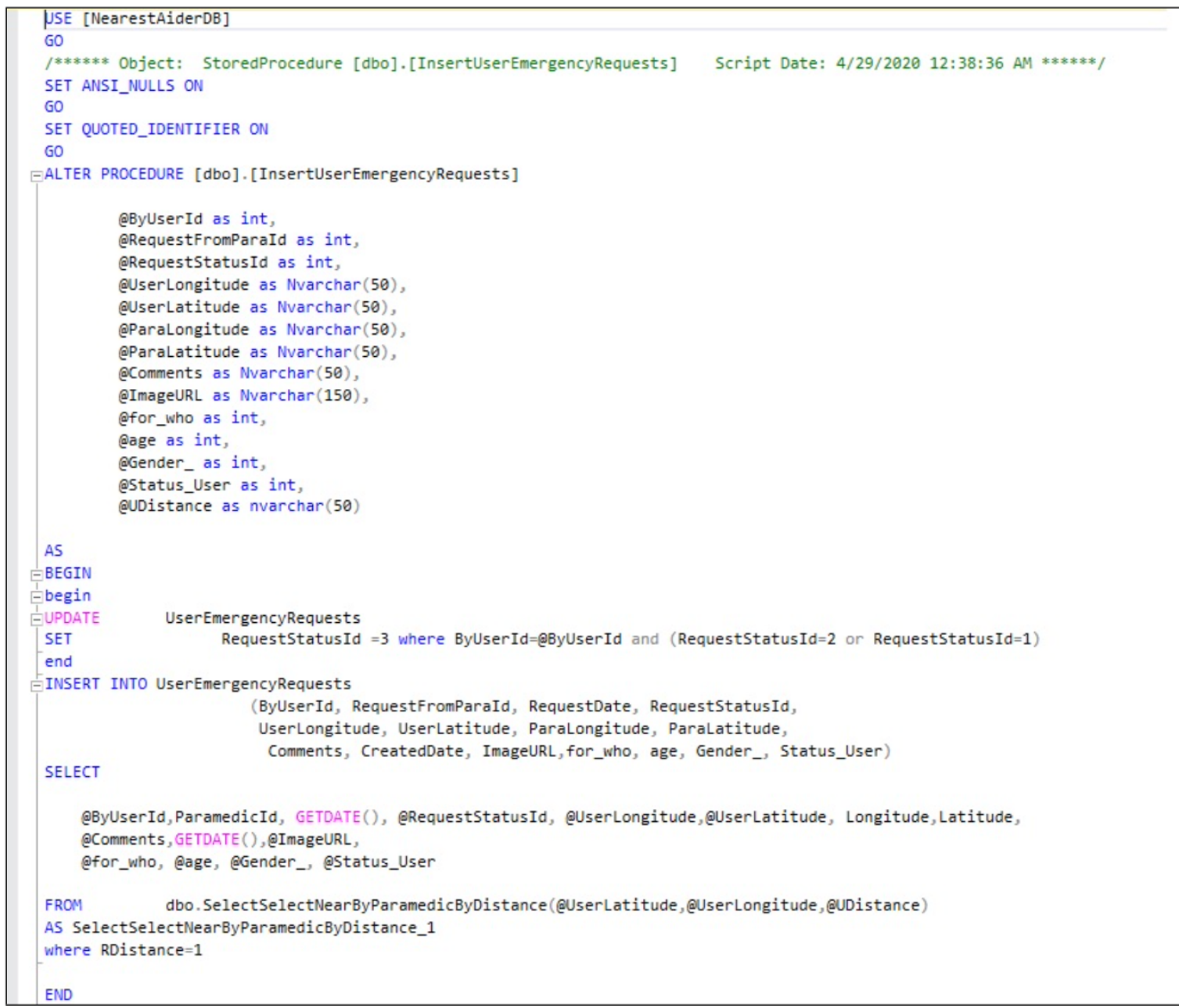

Figure 12: A stored procedure to insert and store information about a request.

Advances in Distributed Computing and

Artificial Intelligence Journal

(c)Ediciones Universidad de Salamanca / cc by-nc-nd
ADCAIJ, Regular Issue Vol 3 n.3 (2015)

http://adcaij.usal.es 


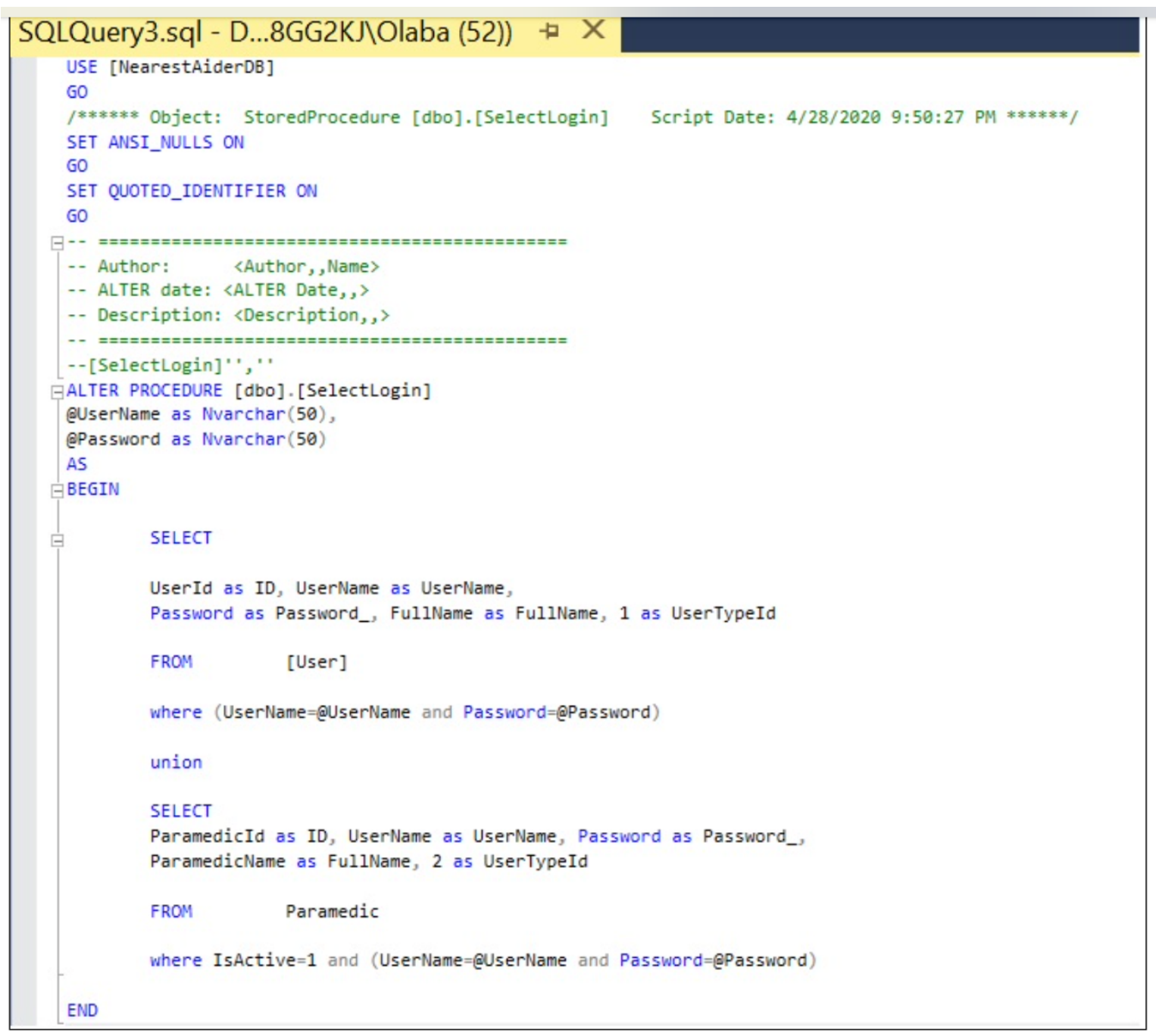

Figure 13: A stored procedure to retrieve Log In information for confirmation.

Advances in Distributed Computing and

Artificial Intelligence Journal

(c)Ediciones Universidad de Salamanca / cc by-nc-nd
ADCAIJ, Regular Issue Vol 3 n.3 (2015) http://adcaij.usal.es 


\section{Usability Test}

Usability testing is the relation between the tools and the user they allow patrons to perform tasks or uses in the best possible way. This means that it can be used by the beneficiaries. It is the degree of success of the beneficiary in learning and using the product to achieve a specific goal. Our system functions will be tested by following Nielsen criteria which are ten criteria (Jeffrey Rubin and Spool, 2008; Smart, 2004). We choose five of the Nielsen criteria which are the most effective criteria that help to apply the usability test .

Learnability: How easy is it for users to accomplish basic tasks the first time they en- counter the design?

Efficiency: Once users have learned the design; how quickly can they perform tasks?

Memorability: When users return to the design after a period of not using it, how easily can they establish proficiency?

Errors: How many errors does user make, how severe are these errors?

Satisfaction: How pleasant is it to use the design?

We performed the usability testing, we will use android studio with Nearest aider application, testing by users to get feedback. We evaluate the application's functionalities according to Nielsen criteria.

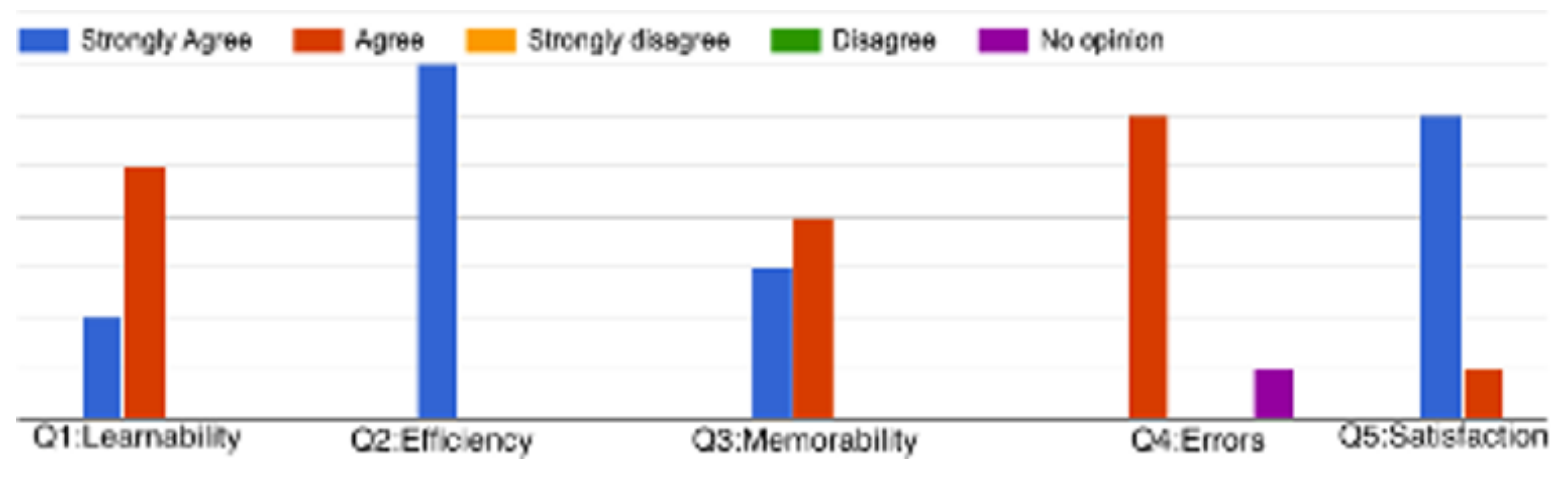

Figure 14: Nearest aider application survey.

The statistics on first question which is (Learnability: How easy is it for users to accomplish basic tasks the first time they encounter the design?) show that 2 of 7 users strongly agrees with functions test and 5 of 7 just agrees, as shown in Figure 6.1 on first and second columns.

The third column in Figure 14 shows the statistical result of the second question which is (Efficiency: Once users have learned the design, how quickly can they perform tasks?), as shown 7 of 7 users strongly agrees with functional test. The fourth and fifth columns in Figure 14 present the statistical results of the third question which is (Memorability: When users return to the design after a period of not using it, how easily can they establish proficiency?) the statistics show that 2 of 7 users strongly agrees with functions test and 5 of 7 just agrees.

The fourth question statistics produced the sixth and seventh columns in Figure 14. These question measure errors (Errors: How many errors do users make, how severe are these errors?) the statistics show that 6 of 7 users 
agrees with functions test and 1 of 7 just no opinion.

The statistics of the fifth question which is (Satisfactory: How pleasant is it to use the design?) produced the sixth and seventh columns which show that 6 of 7 users strongly agree with functions test and 1 of 7 just agrees.

\section{Conclusion and Future Work}

ASAFNY is a phone application developed by the Red Crescent Authority. The application helps in requesting an ambulance and sharing the location (Authority, 2019). To get an outlook of the people's response to the application, a survey was established. After collecting the data of 189 respondents and analyzing them, the results showed that $51 \%$ of the respondents did not know about ASAFNY and 44\% replied that the application simply did not work. After contacting the Red Crescent Authority to inquire more about the issue, they confirmed that the application had some problems and had a complex interface that proved not helpful in emergency situations. The proposed project was also discussed with the Red Crescent representative and he encouraged it and suggested using the ASAFNY application for ideas and to find a way to integrate the project with ASAFNY. After getting a preliminary approval of sponsorship from the Saudi Red Crescent Authority in Jeddah, the request was submitted to the management in Riyadh. However, the management in Riyadh was unable to affirm the approval because of legal reasons since they are working with a private software company.

The following list represents the aims hopefully achieved by the end of this project:

- Connect between the injured and the nearest first aider

- Provide the injured with better and faster treatment

- Increase the social responsibility of our society

- Increase the social awareness of the positive impact of first aid training

Due to the limited time and extensive/complex range of possible enhancing elements, we were left in a hesitant position while deciding which of these elements is efficient for the project. A list of possibilities are conducted, and hopefully, with an appropriate course of testing and user feedback, the project could reach its optimum potentials.

The following list presents recommended future work:

- Supporting multiple languages to attend to a wider range of users

- Adding phone number verification for more security and quicker registration/sign in

- Expanding the website's structure and access authorities according to the hierarchical structure of the organization that will use the system

- Adding a way of live communication between the aider and user

- Expanding the application's usability to be inclusive of users with different handicaps

Advances in Distributed Computing and

Artificial Intelligence Journal

(C)Ediciones Universidad de Salamanca / cc by-nc-nd
ADCAIJ, Regular Issue Vol 3 n.3 (2015)

http://adcaij.usal.es 
- Designing and testing multiple interface designs to decide which elements would offer a better user experience.

\section{References}

Al-Mrayeh, K., 2018. ASAFNY Application for Smartphones. Okaz.

Alblwi, A., 2017. Delayed ambulance kills 70\% of casualties. Alriyadh.

Aljaber, M., 2018. How many are the residents of Saudi Arabia and what the percentage of males and females is? Alarabiya.

Authority, S. R. C., 2018a. 1436/1437 Hijrii annual report summary. https://www.srca.org.sa/ar/ Statistics/AnnualReport. Accessed: Sep. 2019.

Authority, S. R. C., 2018b. About the authority. https://www.srca.org.sa/ar/About/About.

Authority, S. R. C., 2019. SRCA mobile applications. https://www.srca.org. sa/en/MobileApp. Accessed: Nov. 2019.

Bank, T. W., 2019. Population, total -Saudi Arabia. https://data.worldbank.org/indicator/SP.POP . TOTL? locations=SA. Accessed: Oct. 2019.

Elyashiv, E., 2018. How technology can help first responders save lives. The Technology that Drives Government IT, GCN.

Igwenagu, H., 2016. Fundamentals of research methodology and data collection. LAP Lambert Academic Publishing. ISBN 978-3-659-86884-9.

Jeffrey Rubin, D. C. and Spool, J., 2008. Handbook of usability testing: how to plan, design and conduct effective tests. Wiley.

Newspaper, M., 2016. Converting red crescent communications electronically and tablet as a wireless alternative. Makkah.

for Security Operations, N. C., 2019. Auto-Answer System 991. http://bit.1y/2oIzEZO. Accessed: Nov. 2019.

Smart, K. L., 2004. Usability Testing: Developing Useful and Usable Products. Ph.D. thesis, Miami University of Ohio.

for Statistics, G. A., 2017. The total population. https://www.stats.gov.sa/en/indicators/1. Accessed: Oct. 2019.

Uber, 2019a. Driving safety forwards. https://www.uber.com/sa/en/ride/safety/. Accessed: Nov. 2019.

Uber, 2019b. How to use the Uber app. https://www.uber.com/sa/en/about/how-does-uber-work/. Accessed: Nov. 2019.

Uber, 2019c. Use Uber in cities around the world. https://www.uber.com/global/en/cities/. Accessed: Nov. 2019.

What3words, 2019. What is what3words? https://what3words.com/about-us/. Accessed: Nov. 2019.

Advances in Distributed Computing and

Artificial Intelligence Journal

(c)Ediciones Universidad de Salamanca / cc by-nc-nd
ADCAIJ, Regular Issue Vol 3 n.3 (2015)

http://adcaij.usal.es 